\title{
Chapter 1 \\ Science and Society an Overview of the Problem
}

\begin{abstract}
Science in the recent past promised to society to contribute to the grand challenges of the United Nations, UNESCO, WHO, the EU agenda and national agendas for change and improvement of our life, the human condition. In this chapter it will be briefly discussed how this social contract between science and society has developed since 1945. In the context of this book I distinguish three time periods, but I do realize slightly different time periods may be preferred, based on the perspective taken. The first phase from 1945 till 1960 is characterized by autonomy, building on the successes of the natural sciences and engineering in World War II. In the second phase, the late sixties till approximately 1980, government and the public lost trust and saw the downside of science and technology. The response from politics and the public was to call for societal and political responsible research inspired by broader socio-political developments in society. The third phase from 1990 till 2010 was one of renewed enthusiasm and hope that science and technology would bring economic growth, which should make nations internationally competitive. There increasingly was also room for societal problems related to environment and sustainability, health and well-being. In this approach of the so-called knowledge economy, with the world-wide embracing of neoliberal politics, strong relations with government and the private sector were established. This was accompanied by short-term accountability, control from government and funders at the level of project output, using accordingly defined metrics and indicators. Because of this, this model became firmly and globally institutionalized.
\end{abstract}

It is beyond any doubt that knowledge and innovation are more than ever critically needed to address the current global problems of society that affect our lives, that scientific investigation and the huge public investments involved, could have and must have significantly more impact. This is echoed and pursued by governments, NGO's and others in recent reports and strategic plans (UN, EU, UNESCO, IS7). Do we need such frequent calls upon the responsibility of the science community? Aren't they engaged? Do I need to write this book? Indeed, the calls upon science are timely as ever before, one must say. It is timely and rather urgent for quite different reasons. The factors I will discuss here relate to how science and academia have become and, in many ways still are organized and how this affects and distorts 
productive interactions between science and society. From the perspective of society this results in suboptimal agenda setting and thus suboptimal return on investment in science's contribution to the major societal issues of our time and age. Before doing so, I will, like virtually every writer about science, scientific inquiry and academia, make it very clear, that science ${ }^{1}$ has produced and is producing many important results. The 'hard' natural sciences in particular since the industrial revolution have had enormous impact on the human condition, on the quality of our lives. Scientific investigation and the community of its practitioners had in the seventeenth century gone through a critical change which enabled production of solid and practical knowledge that could be tested and certified (Cohen, 2010; Shapin, 1996). This relates in particular to the various fields of natural sciences like physics, chemistry and engineering. In the twentieth century it has been followed with major progress in especially biomedical research and the geosciences, but also research in psychology, sociology, economy, history and ethics and philosophy have irreversibly changed our lives. New sources of energy, transport and communication, availability of clean water, improvement of general public health mainly through novel measures of hygiene, vaccination and antibiotics, improvement and efficiency of industrial production have impacted our material quality of life. Despite the criticism and the mistrust in science, especially when it brings insights with potentially socially or economically unpleasant consequences, the way scientific knowledge is produced makes it the best institution we have to increase our understanding of the world we live in and understanding ourselves and our life.

Science is a community of peers that puts new findings and claims to the test, that purges and filters it to become robust, reliable, objective and trustworthy knowledge that can guide our actions. At the same time, it keeps producing new knowledge that may, if it survives the reliability tests, replace older beliefs by which mechanism our knowledge growths. This is most accessibly explained by John Ziman $(1978,2000)$.

Having said this, it does not mean that the organisation of science as it has developed in the past 70 years into an international institution cannot be improved to better serve the needs of the various societies and publics around the globe. It is exactly this notion that I am concerned with. It is about the question how knowledge grows. I will discuss which and whose values and ideas about science and society are involved when we determine its excellence and potential impact and how this determines the research agenda through funding and investments decisions. As the growth of knowledge is not autonomous, not random nor guided by the legendary 'invisible hand', it must be possible to improve the impact of science by cognizant governance to aim at better alignment of the research enterprise with our major national and global societal needs.

\footnotetext{
${ }^{1}$ I will use 'science' or 'the sciences" when I mean to say something about research in all academic disciplines which comprise natural, life science, engineering, the social sciences and scholarship in the humanities. I will use 'science' also when I talk about the total of the academic institutional system of knowledge production.
} 
John Dewey in 1948 concludes in his Introduction to the reprint of his Reconstruction in Philosophy (Dewey, 1948), that science had freed us up from religion and 'was regarded a deliberate assault on the morals that were tied up with the religion of Western Europe( $p$ xii),... but the world and rationality of the natural and technical sciences had deeply entered human daily life ( $p$ xiii)'. The natural sciences have thus entered the domain which was initially 'not only the domain of religious belief and practices, but of virtually all institutions that have been established before the rise of modern science ( $p$ xiii)'. By doing so, he concluded that the original compromise to keep these fields separated, to keep science insulated, had failed. He called for systematic deep philosophical analysis of how that has come about, how it had distorted the old institutions and how we should deal with the significant novel moral issues that come with it. Despite all the technological benefits 'this had not resulted in a world with more security, peace, better governance and higher moral standards'. This clear critique of the adverse effects of modernity was a broad theme in the thinking of American pragmatism. The use of nuclear weapons, which had happened just 3 years before Dewey wrote these lines, was for many, including leading physicists as Einstein the reason to critically reflect on the societal impact and responsibility of science. Dewey: 'The development of scientific inquiry is immature; it has not as yet got beyond the physical and physiological aspects of human concerns, interests and subject matters. The institutional conditions into which it enters, and which determine its human consequences have not yet been subjected to any serious, systematic inquiry worthy of being designated scientific' (p xv) (Dewey, 1948).

I leave it to the reader to reflect on the relevance of these observations for our times. Obviously, science which formally in the US National Science Foundation (NSF) only since 1958 next to the natural sciences includes the social sciences, humanities and engineering, has grown and matured and has become a major global factor in virtually all aspects and domains of public, private and social human life. The relationship between science and society has therefore even become more intricate, more complicated and at the same time more critical regarding the major societal challenges we are facing in the third decade of the twenty-first century.

\subsection{A Call for Action}

The very week in October 2019, that I started the actual writing of this chapter, Nature featured an Editorial on the massive and sad waste in the global food supply system evidenced by research. In the same issue a major big data research paper on mortality in very young children showing global improvement, but still great inequalities in preventable mortality between different geographical regions. In the accompanying comment Michelle Bachelet, a former president of Chile and paediatrician with hands on experience of this problem in that country, argues for an integrated research approach to understand the causes in terms not simply of access to health care, but of 'broader ills: poverty, disempowerment, discrimination and injustice'. 'Hard data', she writes, 'must be followed up by action across a whole 
spectrum of government and society' (Bachelet, 2019). In that same issue of Nature, Diane Coyle, well known from 'The Economics of Enough', published a review of three recent books on economics by prominent authors and closes of with a couple of very gloomy lines: 'as Soros asserts that intellectual framework of economics must adapt to a world ever more removed from a focus on individual choices. This trend is under way in economics, but a radical rethink is unlikely there: the incentives of academia encourage conservatism and incremental progress". She continues: 'Better metrics and theories will not be enough to create a sustainable economic and social model. Or they could-but only if they convince policymakers and the public to act differently'. As the final blow she adds: 'The future of capitalism is out of the hands of those who spend their time thinking about it' (Coyle, 2019). That same week in an editorial in Science, Ian Boyd chairman of the UK Research Integrity Office, reflects with a strong sense of urgency on the failing interaction between scientists and government and politics (Boyd, 2019). Science should engage more with government and the public debates and let itself not be put in a box with a tight lid on it and being manipulated to become yet another 'money grabbing vested interest'. 'Advocacy is the surest and most rapid way to achieve such an effect', he argues 'although science should not be captured by normal politics'.

These quotes all argue, although in slightly different ways, that science, academic research should aim to have an effect in the real world. As I have argued: ' $A$ paper in Nature does not cure patients'. It does not change the life expectancy of young children, global socioeconomic systems and policies, the politics, logistics and trade of food, unless it is put into practice, translated to actions to change the condition of those whose quality of life is affected by the problem under study. Science, these writers in October 2019 say, in order to contribute and impact on society, has to connect with the publics, the stakeholders out there who have an interest, an expectation getting a problem solved, having their lives improved. It must result in actions, that then will be put to the test in practice. In this pick of weekend reading of October 19 and 20, 2019, the issues of socioeconomic inequality, public health, societal injustice and food waste are featured, but we also know of grand challenges like climate change; the transition to fossil-free energy; the threats to democracy and its institutions, which includes threats to science by populism and nationalism. In the twenty-first century, challenges are complex, mostly non-linear, which needs a different approach compared to most of the science done before (Beck, 1992; Nowotny, 2016). Science, to be effective must be much more missionoriented, inclusive, truly multidisciplinary. It should drive not mainly for economic and technological impact, but should also target public and social needs and keep in mind that technology for many problems is not the only solution as it reception by the public will often be poorly understood. Social sciences and humanities (SSH) have to engage since major issues in modern life are in the social and political domain where SSH including economy and political sciences have a lot to offer. The UN has defined seventeen Sustainable Development Goals (SDGs) that must be taken on through science and innovation. ${ }^{2}$ To address these goals, breakthrough

${ }^{2}$ https://www.un.org/sustainabledevelopment/sustainable-development-goals/ 
knowledge and solutions will not only come from the natural, biomedical sciences and engineering (STEM). Major issues in these domains relate to problems that need to be investigated in a truly integrated way by researchers from STEM and SSH.

\subsection{The Social Contract for Science, What's the Problem?}

Why do these authors feel that they have to make these strong pledges to science and the academic community to not only investigate and publish, but to take their academic results one stage further and engage throughout with the relevant agents, policy makers and publics and citizens to which the societal issues matter? What's wrong here? Isn't it, that almost every website of universities and academic institutions around the globe says that its mission, ambitions and strategy are to contribute to the quality of life by excellent research and teaching? That even in most cases explicit societal themes and targets have been chosen in agreement with the UN SDGs?

From the perspective of the public, policymakers, charities and public and private funders one would indeed trust and expect that academic science would be fully geared towards maximal and optimal impact to address and alleviate conditions that interfere with the good life and to address human needs at whatever level in society: personal, structural or political. That is why we think large amounts of public tax money are invested, or to state it more realistic, are being spent.

The relationship, however, between governmental and charity funders and the researchers which have in the previous century become organised in academic institutions and governmental agencies is not that simple. The study of the history of science and its institutions in particular from World War 2 (WW2) on, shows that he connection and interaction between science and society is quite complex and that the aims of the scientific community on the one hand and government and the public on the other, are not always well aligned. The collective of institutions and the community of research and science has developed since 1945, as the result of a vigorous political debate in the USA as in other western countries. (Kleinman) (Guston \& Keniston, 1994; Sarewitz, 1996, 2016) In the USA this resulted in the famous Social Contract for Science in which science was governed by scientists, spending public money without influence or interference by government. Science did rely on its own distinct dynamics in academia, in the different (sub)disciplines, faculties and institutes of universities and in the highly respected and influential learned societies.

Science has thus been established as a 'state in a state', the Scientific Estate (Price, 1965) or the Republic of Science (Polanyi, 1962b), with its own goals, rules, governance, ethics and (counter)norms (Bourdieu, 2004; Latour, 1987; Merton, 1973; Ziman, 2000) Its culture and politics are until this day largely determined by old ideas originating from the first half of the twentieth century - from the classical philosophy and sociology of science about how science ought to be done. It still has that mythical narrative about 'the scientific method' of the 'hard' sciences, 'pure versus applied', about 'the relation between science and technology' and 'the linear 
model of innovation' which Vannevar Bush so effectively used to establish the Scientific Estate at the end of WW2. It is still used in the public debates to defend public funding and importantly secure autonomous governance for science and academia (Bush \& United States. Office of Scientific Research and Development, 1945; Greenhill, 2000; Kleinman, 1995). Moreover, as I will argue in detail in the following Chapters, it determines to a great deal still our academic culture: how excellence and quality is defined and how choices regarding the research agenda are made but also how it affects diversity and inclusiveness of research and researchers in academia.

\subsection{Politics Outside In}

In the scientific community and academia there are like in all institutions strong and sometimes opposing ideas at play about how science as a societal force for progress should be organized, positioned and governed in society in relation to need and expectations of the public. How it should be facilitated to be able to show maximal progress and finally and most relevant, how and by whom quality and progress is to be defined. These debates are in some respects quite academic and may sound esoteric but are in fact highly relevant for the daily practice of research. They directly affect questions regarding the effects of internal and external powers in science, for instance regarding internal distribution of credit which involves measures of excellence, academic hierarchies, positions, standing and esteem, allocation of grant money. These politics of science directly and indirectly determine problem choice and thus the growth of knowledge and also the impact of science in a wider societal context. The reader could get the impression from this historical approach and my dominant reference of the seminal works of the second half of previous century, that this mainly is a problem of the past. Make no mistake, unfortunately, that is not the case, as recent empirical work has shown and will be discussed in the following chapters (Fochler \& de Rijcke, 2017; Franssen et al., 2018; Hammarfelt \& de Rijcke, 2014; Hammarfelt et al., 2017; Kaltenbrunner \& de Rijcke, 2016; Müller \& de Rijcke, 2017; Rushforth \& de Rijcke, 2015; Rushforth et al., 2018; Rushforth \& de Rijcke, 2016).

This relates to persistence of classical ideas about the scientific method, truth, value-free science, academic autonomy, neutrality and the insulation of science from external non-scientific values, from politics and from society at large. These problems of engagement and responsibility, versus autonomy and academic freedom are not at all new and have been discussed in the sixties and seventies from different philosophical, sociological and political viewpoints (Rose \& Rose, 1969; Ziman, 1996; Ravetz, 1971; Bernal, 1939; Polanyi, 1962b; Habermas, 1970a, b; Toulmin, 1964; Weinberg, 1963).

From 1960 the idea of science as a communitive action, a truly collective and social process with a professional culture organized to produce certified and robust knowledge became established. In particular since Kuhn's Structure of Scientific 
Revolutions published in 1962, in academia it became acceptable and was recognized indispensable to study the various social aspects of science taking into account, other than strict scientific arguments to be able to explain the growth of knowledge (Kuhn, 1962). These developments originated from ground-breaking work by a few scholars that in a novel way started to perform studies of how science works and how we make and accept knowledge (Hanson, 1958; Toulmin, 1972; Polanyi, 1962a; Ziman, 1968). Their studies deviated from the until then dominant mainly normative philosophical discussion based on the natural sciences on the status of scientific claims, and instead focused on the practice of science and how knowledge and our common beliefs in practice are reached, instead of discussing how science ought to be done. As I will discuss later, despite that this work goes back 40-60 years, since it was mainly performed in the social sciences and humanities faculties, in the faculties of natural sciences, geoscience and biomedical sciences, this still has not been widely noticed. The majority of practitioners and administrators intuitively still go by the Standard Model, a popular image of science that does not correspond with the actual aim and practice of science. The classical ideologized images of science and its poor match with the actual practices of knowledge making, is highly problematic since until this day it determines to a large extend how science is being done in academia. Obviously, a correct selfunderstanding of science is also of particular importance in debates where proper reflection on the status, the higher purpose and the position of science in society is required (Habermas, 1971).

\subsection{The Social Contract of Science Revisited}

Despite its own mythical claims of autonomy and of pure investigator-driven research as the highest ideal, science, especially natural science and engineering, but increasingly biomedical research from 1945 on, was driven and had grown immensely by infusion of public money that targeting mainly public issues of health and agriculture. In addition, science around the globe remained heavily connected to the corporate and military sector, also in times of peace after WW2. In the US investments especially the natural sciences were boosted by Eisenhower in reaction to the hysteria in science and education prompted by the first successful manned Soviet spaceflight of Sputnik in 1958 (Greenberg, 1999). In private discussions at that time with his adviser James R. Killian, a former president of MIT, Eisenhower expressed his irritation about scientists who pursued their own interests instead of those of the nation with their work having too little benefit for society and its publics. Interestingly, despite this reprise of Vannevar Bush's agenda of 1945 now provoked by Sputnik and the Cold War, Eisenhower in his famous farewell speech 17 January 1961 expressed his deep worries about the fact that science had been hijacked by the military and the commercial interests of the connected industries.

This boost of the natural sciences in the USA seems in some respect in agreement with C.P. Snow's even more famous, bold and original cultural and 
philosophical critique of academia and science in his 'The Two Cultures' (Snow, 1993). He argued in 1959 that academia in the UK held theoretical, pure scholarship of the humanities in much higher esteem than research in the natural sciences with their technical and practical applications. Stefan Collini in his most insightful introduction to the 1993 reprinting of Snow's book, elaborates on its cultural and social background, reception and the brutal dismissal by F.R. Leavis. Collini states the following: 'The 'Leavis-Snow controversy' can obviously be seen a re-enacting of a familiar clash in English cultural history- the Romantic versus the Utilitarian, Coleridge versus Bentham, Arnold versus Huxley and other less celebrated examples (pxxxv.) Snow, according to Collini, was 'clearly frustrated about the domination of the traditionally educated upper class and was motivated by class resentment' which places the 'The Two Cultures' also in a much larger and moral socio-political context than science. In the Second Look, indeed Snow confesses that the original title 'Rich and Poor' would have been better suited for his argument. He ends the book after he discusses major social and economic problems as follows: 'With good fortune, however, we can educate a large proportion of our better minds so that they are not ignorant of imaginative experience, both in arts and science, not ignorant of the endowments of applied science, of the remediable suffering of most of our fellow humans, and of the responsibilities which, once they are seen, cannot be denied'(p100).

Eight years later, Peter Medawar, a famous observer of science, immunologist and Nobel prize winner, made a similar observation from within his domain of the biomedical sciences. His critique was based on the 'pure versus applied' distinction and he discussed the 'motives which have led people to think (it) (these different forms of research) highly important, and above all to make it the basis of an intellectual class-distinction.' (p120) (Medawar, 1967). 'The two conceptions are, roughly speaking, the romantic and the rational, or the poetic and analytical, the one speaking for imaginative insight and the other for the evidence of senses, one finding in scientific research its own reward, the other calling for a valuation in the currency of practical use' (p10-11). 'The notion of purity has somehow been superimposed upon it (Bacon's distinction) and in a new usage that connotes a conscious and inexplicable sight-righteous disengagement form pressures of necessity and use. The distinction is....between polite and rude learning, between laudable useless and the vulgar applied, the free and intellectually compromised, the poetic and the mundane' (p121-212). While pure science is a genteel and even creditable activity for scientists in universities, applied science, with all its horrid connotations of trade, has no place on the campus'(p126).

Medawar, who came very early in his life with his parents from Brazil to England and studied at Oxford, came from comparable social backgrounds as Snow, outside the traditional social elites (Collini here cites Trilling pxxxix). Medawar interprets these two distinct conceptions and cultures of science in the larger social cultural Anglo-Saxon context, which was 'terribly English', he remarks. Both clearly see the unproductive cultural and philosophic tension that even affects the organizational level of the academy. They argue explicitly for a proper balance between science and humanities, but also for a balance of pure and applied within the science 
disciplines. They see this social and cultural divide and its academic hierarchy as obstructive to optimal societal impact of scientific research and of the academia as an institution. Medawar explicitly discusses criteria of (e)valuation of science, in his opinion being the 'size of ..contribution to that huge, logically articulated structure of ideas' and for humanists 'by different but equally honourable standards, particularly by the contribution it makes, directly or indirectly, to our understanding of human nature and conduct, and human sensibility' (p126).

Medawar states that 'pure' nor 'applied' are specific criteria for evaluation of research. With the hindsight of 2019, we know, as we shall discuss later, that in the unwritten and written mores they most surely were, and to great extent still are and not only in the UK. Medawar at the same time concludes with a visionary remark that 'The humanist fears that if we abandon the ideal of pure knowledge, knowledge acquired for its own sake, then usefulness becomes the only measure of merit. And that if it does become so, research in the human arts is doomed' (p126).

This is indeed the major worry from the domain of humanities that Snow and Medawar, despite their complaints could have anticipated based on what had already happened in the politics of science after the 'coup' of the 'hard sciences' and in particular the physicists lead by Vannevar Bush. Interestingly, philosophers in these same years already saw a major problem with the dominance of the worldview and ideas of modernity and the corresponding reductionist positivist Cartesian way of doing science. This 'scientific method' appeared to have proven quite successful first for the technosciences, the 'hard sciences' and later biology and biomedical research but was not appropriate for the social sciences and humanities. Disciplines that studied the social domain of society and human life need the classical pre-modern methods of arguments, reason and rhetoric (Winch, 1958; Toulmin, 1961, 1972). The present-day academic should not forget that SSH were in academia, in sharp contrast to the centuries before, for a large part of the twentieth century, not considered scientific nor serious rational endeavours. It took an extra 8 years before these disciplines were recognized as science and were included after the start in 1950 of the US National Science Foundation. As we will see later in this book, and as Shapin wrote in 2007, Snow was 'not at a funeral of the natural sciences, but at a christening'. 'In the academy and most modern research universities, it is the natural sciences that have the pride of the place and the humanities and social sciences that look on in envy and sometimes resentment.' (Shapin, 2007).

In the meantime, Project Hindsight, a study on the return of investments in science aiming at military defence ran from 1963 until 1968, that was officially published in 1970. The conclusions were quite shocking for the science establishment. Technology accounted for $91 \%$ of the impact, very little was attributable to applied science and nearly nothing to basic science (Sherwin \& Isenson, 1967). In these days, the critical comments made by President Johnson at the signing ceremony of Medicare (June 1966), about a lack of clinical impact of publicly funded basic biomedical research ('laboratory research') elicited strong protests from the biomedical research community, which can still be heard in many biomedical institutes. 


\subsection{The Politics of Scientific Choice}

As a logical consequence of these critical views and evaluations of science, the unescapable question of how to deal with 'the complexity of scientific choice' came up. In a series of high-profile papers, published at the very start of the journal Minerva, between in 1962-1964. They were written by authorities like Michael Polanyi, Alvin Weinberg, CF Carter and John Maddox and are very reminiscent of the current debates about Incentive and Rewards (Carter, 1963; Maddox, 1964; Polanyi, 1962b; Weinberg, 1963). Stephen Toulmin wrote a review of these papers, discussing the quite different perspectives presented. Up-front he concluded that 'the questions about selection and priorities, implicit in all discussions of science policy are both difficult and inescapable' (Toulmin, 1964). The problem, he writes is there for both less developed and industrialised (developed) countries, but they are of course very different for them (p333). The difficulty is that we know too little about the consequences and long-term impact of in particular fundamental research since we know too little about the course that both science and society will run and which problems will emerge. Toulmin suggests that we therefore should systematically study sociological, economic and organisational questions involved in the interactions between science and society. In addition, he concludes that we need to understand the issues at play in the formulation and administration of a science policy and 'remove any fog due to ambiguities, cross-purposes or hidden assumptions'. Polanyi is well known for his advocacy for the autonomous and self-governed 'Republic of Science'. Its higher aim being to reveal 'a hidden reality for the sake of intellectual satisfaction'. He argues strongly for the scientific community and its internal structures to decide on scientific choice. "Guiding the progress of science into socially beneficent channels' is 'nonsensical' and 'guiding scientific research towards a purpose other than its own, will deflect the advancement of science' (cited by Toulmin). Maddox agrees with him, pointing out that it takes debates between academics (intellectual confrontations and open discussions) to decide on research priorities, which he says will also have to be done for the technological applied sciences. This is all well, hard to do, even within a given branch or subdiscipline, but Weinberg taking the problem to a higher organizational level, is more interests in choices 'which pit different fields against each other, for instance molecular biology, high energy physics and behavioural sciences'. Their potential impact and relevance in science and society is incommensurable. He proposes and elaborates on three criteria's of merit: technological, scientific and social. For massive public support at least two should be highly rated. Social merit is to be decided on external arguments (politics and values) about issues like 'health, food production, defence and prestige'. He, being a physicists, offers some judgement: 'molecular biology has all three merits, but high energy physics is somewhat overrated,... space-research is only masquerading as science, but if it is more on prestige (first man on the moon) or for military impact we should say so'. Carter comes from a very 
utilitarian economic perspective and regarding pure research he believes that 'any nation is at liberty to undertake pure research beyond its justification by its ultimate application'. There is of course no one science policy, says Toulmin, and he points to the many science policy choices that continuously have to be made, in science and governments, as the way these obvious different perspectives, play out in reality. Because of the plurality of problems, in science and society they will be plurality of criteria and merits that are relevant in the many different contexts in which political choices regarding science policy have to be made. He also points out the problematic use of 'the scientists' and 'the scientific community', the lack of democracy of these communities with its 'age-and-status structure' of a gerontocracy which impedes assessing 'the scientific opinion'. There are many interactions and contact points of science with government and these involve many different scientists who will apply 'their minds to a different group of problems and the needs of each partnership will impose their own pattern of research priorities and criteria of choice'. Regards this debate, Toulmin distinguishes also four distinct types of research, from (1) pure natural science to (2) speculative technology, to (3) applied product- oriented and (4) problem-oriented research aimed at solving a particular practical problem that has different stakeholders in science and society. He continues this paragraph with an insightful statement reminiscent of John Dewey's pragmatism that at that time already was nearly forgotten: "The urgent question to-day is, how the republic of science is to be integrated not only into the broader academic confederation, but into the whole community of citizens. For it is on the answer to this question that our broader criteria of scientific choice ultimately depend'.

This thinking was propagated before in the first wave of Science for Society in the UK in 1935 by the so-called 'scientific humanists' including J.D. Bernal, Frederick Soddy and colleagues with their book 'The Frustration of Science' and the founding in 1938 of a new division of the British Association for the Advancement of Science for the social guidance to the progress of science. Followed by the Royal Society's initiative put to the universities in 1945 for 'The Balanced Development of Science in the United Kingdom. All 'at best pointless' in the opinion of Polanyi. For Polanyi opening up science and research to politics and publics and being held responsible for the adverse effects of its research, was an absolute 'no go', which was based on his traumatic experiences in the less open and less democratic societies he had fled from (Guston, 2012). He was thus happy to conclude in 1962 that 'this movement (by Bernal and colleagues) has virtually petered out'. He asks the for him rhetoric question 'Have not even the socialist parties throughout Europe endorsed now the usefulness of the market?" We will see that maybe they did not in 1962, but they really did from 1980 on. His own 'Society for Freedom in Science', however, established in reaction to Bernal et al., after its start in 1944 was also very short lived (Society for Freedom in Science, Nature, July 8, 1944). 


\subsection{Conclusion}

As of this writing, the relations and interactions between science and society and the issues of problem choice for the setting of the science agenda, obviously are still topics of hot debate. They touch upon many crucial aspects of the practice of science, but also on the dangers of the possibility of abuse of science via the immense powers of multinationals in our deregulated neoliberal economies. We have to keep in mind the threat to free scholarship and research in many countries where democracy itself is under threat. Before I discuss the more recent developments in light of these images of science in Chaps. 5, 6 and 7, I will analyse in more detail which images of science are involved, what their status is and where they originate from (Chap. 2). Then I will discuss how they determined and distorted our views, attitudes, policies and the organization and potential of science and its interactions with stakeholders in society (Chap. 3).

\section{References}

Bachelet, M. (2019). Data on child deaths are a call for justice. Nature, 574(7778), 297. https://doi. org/10.1038/d41586-019-03058-6

Beck, U. (1992). Risk society towards a new modernity. Sage.

Bernal, J. D. (1939). The social function of science. G. Routledge \& Sons ltd..

Bourdieu, P. (2004). Science of science and reflexivity. Polity.

Boyd, I. L. (2019). Scientists and politics? Science, 366(6463), 281-281. https://doi.org/10.1126/ science.aaz7996

Bush, V., \& United States. Office of Scientific Research and Development. (1945). Science, the endless frontier a report to the President [text] (pp. 1 online resource (ix, 184 pages illustrations)). Retrieved from HathiTrust Digital Library. Freely available. http://catalog.hathitrust. org/Record/001474927

Carter, C. F. (1963). The distribution of scientific effort. Minerva, 1(2), 172-181. https://doi. org/10.1007/BF01096249

Cohen, H. F. (2010). How modern science came into the world: Four civilizations, one 17thcentury breakthrough. Amsterdam University Press.

Coyle, D. (2019). When capitalisms collide. Nature, 574(7778), 322-324. https://doi.org/10.1038/ d41586-019-03047-9

Dewey, J. (1948). Reconstruction in philosophy (enlarged ed.). Beacon Press.

Fochler, M., \& de Rijcke, S. (2017). Implicated in the Indicator game? An experimental debate. Engaging Science, Technology, and Society, 3, 20. https://doi.org/10.17351/ests2017.108

Franssen, T., Scholten, W., Hessels, L. K., \& de Rijcke, S. (2018). The drawbacks of project funding for epistemic innovation: Comparing institutional affordances and constraints of different types of research funding. Minerva, 56(1), 11-33. https://doi.org/10.1007/s11024-017-9338-9

Greenberg, D. S. (1999). The politics of pure science. University of Chicago Press.

Greenhill, K. M. (2000). Skirmishes on the "endless frontier": Reexamining the role of Vannevar bush as progenitor of U.S. science and technology policy. Polity, 32(4), 633-641. https://doi. org $/ 10.2307 / 3235296$

Guston, D. H. (2012). The pumpkin or the Tiger? Michael Polanyi, Frederick Soddy, and anticipating emerging technologies. Minerva, 50(3), 363-379. https://doi.org/10.1007/s11024-012-9204-8 
Guston, D. H., \& Keniston, K. (1994). The fragile contract : University science and the federal government. MIT Press.

Habermas, J. (1970a). Toward a rational society. Heinemann Educational Books.

Habermas, J. R. (1970b). Towards a rational society: Student protest, science and politics. Beacon Press.

Habermas, J. (1971). Knowledge and human interests. Beacon Press.

Hammarfelt, B., \& de Rijcke, S. (2014). Accountability in context: Effects of research evaluation systems on publication practices, disciplinary norms, and individual working routines in the faculty of arts at Uppsala University. Research Evaluation, 24(1), 63-77. https://doi. org/10.1093/reseval/rvu029

Hammarfelt, B., de Rijcke, S., \& Wouters, P. (2017). From eminent men to excellent universities: University rankings as calculative devices. Minerva, 55(4), 391-411. https://doi.org/10.1007/ s11024-017-9329-x

Hanson, N. R. (1958). Patterns of discovery an inquiry into the conceptual foundations of science. Cambridge University Press.

Kaltenbrunner, W., \& de Rijcke, S. (2016). Quantifying 'output' for evaluation: Administrative knowledge politics and changing epistemic cultures in Dutch law faculties. Science and Public Policy, 44(2), 284-293. https://doi.org/10.1093/scipol/scw064

Kleinman, D. L. (1995). Politics on the endless frontier : Postwar research policy in the United States. Durham Duke University Press.

Kuhn, T. (1962). The structure of scientific revolutions. 2nd edn, enlarged 1970. University of Chicago Press.

Latour, B. (1987). Science in action : How to follow scientists and engineers through society. Harvard University Press.

Maddox, J. (1964). Choice and the scientific community. Minerva, 2(2), 141-159. https://doi. org/10.1007/BF01096591

Medawar, P. S. (1967). The art of the soluble. Methuen.

Merton, R. K. (1973). The sociology of science: Theoretical and empirical investigations. University of Chicago Press.

Müller, R., \& de Rijcke, S. (2017). Thinking with indicators. Exploring the epistemic impacts of academic performance indicators in the life sciences. Research Evaluation, 26(3), 157-168.

Nowotny, H. (2016). The cunning of uncertainty. Polity.

Polanyi, M. (1962a). Personal knowledge ; towards a post-critical philosophy. Harper Torch Books.

Polanyi, M. (1962b). The republic of science. Minerva, 1(1), 54-73. https://doi.org/10.1007/ BF01101453

Price, D. K. (1965). The scientific estate. Belknap Press of Harvard University Press.

Ravetz, J. R. (1971). Scientific knowledge and its social problems. Clarendon Press.

Rose, H., \& Rose, S. P. R. (1969). Science and society. Allen Lane.

Rushforth, A., \& de Rijcke, S. (2015). Accounting for impact? The journal impact factor and the making of biomedical research in the Netherlands. Minerva, 53(2), 117-139. https://doi. org/10.1007/s11024-015-9274-5

Rushforth, A. D., \& de Rijcke, S. (2016). Quality monitoring in transition: The challenge of evaluating translational research programs in academic biomedicine. Science and Public Policy. https://doi.org/10.1093/scipol/scw078

Rushforth, A., Franssen, T., \& de Rijcke, S. (2018). Portfolios of worth: Capitalizing on basic and clinical problems in biomedical research groups. Science, Technology, \& Human Values, 44(2), 209-236. https://doi.org/10.1177/0162243918786431

Sarewitz, D. R. (1996). Frontiers of illusion : Science, technology, and the politics of progress. Temple University Press.

Sarewitz, D. R. (2016). Saving science. The New Atlantis, 49, 4-40.

Shapin, S. (1996). The scientific revolution. University of Chicago Press.

Shapin, S. (2007). Science in the modern world. In O. A. E. Hackett, M. Lynch, \& J. Wajcman (Eds.), The handbook of science and technology studies (3rd ed., pp. 433-448). MIT Press. 
Sherwin, C. W., \& Isenson, R. S. (1967). Project hindsight. Science, 156(3782), 1571-1577. https://doi.org/10.1126/science.156.3782.1571

Snow, C. P. (1993). The two cultures. Cambridge Unversity Press.

Toulmin, S. (1961). Foresight and understanding; an enquiry into the aims of science. Indiana University Press.

Toulmin, S. (1964). The complexity of scientific choice: A stocktaking. Minerva, 2(3), 343-359. https://doi.org/10.1007/BF01097322

Toulmin, S. (1972). Human understanding. Clarendon Press.

Weinberg, A. M. (1963). Criteria for scientific choice. Minerva, 1(2), 159-171. https://doi. org/10.1007/BF01096248

Winch, P. (1958). The idea of a social science and its relation to philosophy. Routledge and Kegan Paul Humanities Press.

Ziman, J. (1968). Public knowledge : An essay concerning the social dimension of science. Cambridge University Press.

Ziman, J. M. (1978). Reliable knowledge : An exploration of the grounds for belief in science. Cambridge University Press.

Ziman, J. (1996). Is science losing its objectivity? Nature, 382(6594), 751-754. https://doi. org/10.1038/382751a0

Ziman, J. M. (2000). Real science : What it is, and what it means. Cambridge University Press.

Open Access This chapter is licensed under the terms of the Creative Commons Attribution 4.0 International License (http://creativecommons.org/licenses/by/4.0/), which permits use, sharing, adaptation, distribution and reproduction in any medium or format, as long as you give appropriate credit to the original author(s) and the source, provide a link to the Creative Commons license and indicate if changes were made.

The images or other third party material in this chapter are included in the chapter's Creative Commons license, unless indicated otherwise in a credit line to the material. If material is not included in the chapter's Creative Commons license and your intended use is not permitted by statutory regulation or exceeds the permitted use, you will need to obtain permission directly from the copyright holder. 